\title{
EXAM CELL AUTOMATION SYSTEM AND RESULT ANALYSIS
}

\author{
Abha Jain', Aabhas Mathur², Anubhooti Jain ${ }^{3}$ \\ E_mail Id: abhajain005@gmail.com¹, aabhas08mathur@gmail.com², anubhootijain0011@gmail.com ${ }^{3}$ \\ ${ }_{1,2}$ Department of Electronics \& Comm. Engineering, Aravali Institute of Technical Studies, Udaipur, India \\ ${ }^{3 s}$ Department of Electronics \& Comm. Engineering, Geetanjali Institute of Technical Studies, Udaipur, India
}

Abstract- In colleges and universities, mostly the exam cell activities can be completed on paper. Using automation system in this field will help in making all the exam cell activities more efficient and easy by overcoming major disadvantages of manual system like faster speed, accuracy and simplicity. Automation in this system will bring more convenience for both staff members and students. Centralization in this system will confirm that the work related to this examination will be managed properly and effectively by making it easier in short time. The computerized system will completely replace offline and manual system. This system will gain more popularity as large and unmanageable data on paper collected from various department of college and its analysis for making result convert it into very tedious task. The centralized system in this cell is midway resolution for both staff and students which makes their work very easy. This system makes the exam cell activities in much organized way. The system obviously requires some pre-existing data, which generates dependency on other system but it reduces paper work, decrease confusion, increase ease of accountability and work efficiency. The research will firstly show access of various users like admin, exam cell staff, students and faculty members. Then customization of the system will depend on the requirement of the college and lastly automated result analysis and ancillary services.

Keywords: Examination center, automation, student user, result.

\section{INTRODUCTION}

Exam cell plays very crucial role in college management system. For an engineering student, exam is significant and foremost issue. Therefore, its management is very big concern and requires lots of efforts. The main challenge of an organization is to track, centralize and solve the issues of students during and after their examination, coordinate various activities, provide proper instructions and better result based education. There are different problems faced by various institutions which are as follows:

$>$ Operations is centered in administrative offices.

$>$ Information and data requires timely updating.

$>$ Information is inconsistent replicated

\section{PROBLEMS IN EXISITNG SYSTEM}

Due to existing manual paper work and calculation system of examination, the amount of work makes the exam cell more tedious and slow and management of this important document is again very tedious task. Handling of such documents requires large amount of time. Also students have to do lot of manual work from filling exam form to collecting of their results. Therefore, there is a great need of some better system like automation.

\section{OBJECTIVE}

$>$ To generate an integrated ERP module.

$>$ To overcome the problem of handwork by bringing centralized system in pre and post examination system.

$>$ To make the system simpler for students, faculty and exam cell department.

$>$ Providing direct access to the exam related notifications, admit card, results.

$>$ Provide direct access to student's performance to teachers.

Our research consists of two main users:

$>$ A. Admin

$>$ B. Student

\subsection{Admin user}

Role of admin is as follows:

$>$ Uploading the previous year question papers

$>$ Issue of admit card

$>$ Updating of notification related to exam dates

$>$ Result generation

$>$ Statistical analysis of result

\subsection{Student User}

Student will perform the following activities: 
$>$ Login

For regular form filling just click on acknowledgement receipt

$>$ View and download their hall tickets.

$>$ View their result online

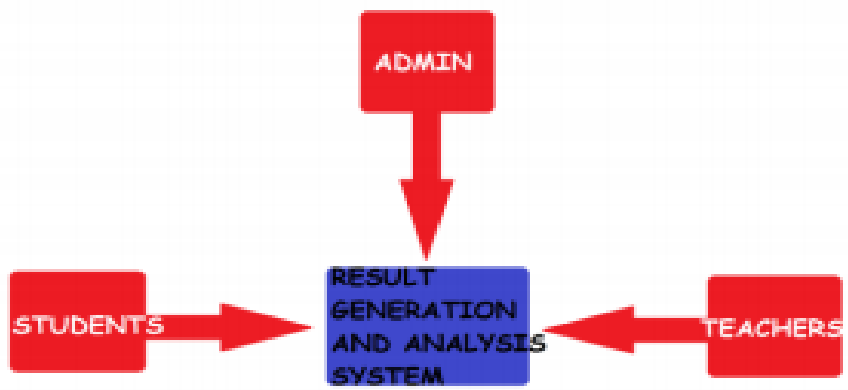

Fig. 3.1 Block Diagram of System

\section{STUDENT ACTIVITIES}

\subsection{Login}

Students have to login with their id and passwords and those who are new on this portal have to register with their new IDs and password. Registered students have option to change or reset their password. The authentication and authorization is handled using spring system.

\subsection{Form Filling}

It is one of the most important feature of exam cell module. This online filling of form helps the students to fill all the necessary information by their own without waiting in any type of line. It also helps in maintaining all the documents of exam cell in digital way which is easier to manage and function well of the exam cell.Student can avail the form online from his/her account any time he/she want. The student may have to make payment for the forms (as the case may apply) and when the status of payment is confirmed in the ERP module, the form is made available to the student.

\subsection{Generation of Admit Card}

It can be generated when seat number is generated. Students can access their hall ticket when admin can make available their ticket on dashboard. The ERP module fetches seat no. and other information like name, roll no., semester, branch, year etc. It populates these data into a hall ticket template. Once the retrieval and populating data to template is successful the ERP module makes the Hall Ticket available for printing.

On the other hand, students are provided edit option to ensure if any error has not been occurred on their hall ticket information in their student module. The students can request to change their information by applying for it in detail. Similarly, admin department has to check and verifies the changes and make relevant changes in their hall ticket and dispatch the admit card to the student.

\section{ADMIN SIDE ACTIVITIES}

\subsection{Seat Number Generation/ Examination Roll Number}

The Examination Roll Number has a particular logic. It involves particular inputs based on which the Exam roll number would be generated. Once the admin enters the above fields and clicks the Assign Seat button, the generation of Seat Numbers or Exam Roll Number begins. There would be a separate table called Seat Number for particular year. It would have its attributes as Roll Number of student and Exam roll number wherein roll number acts as both primary and foreign key. Generated Seat numbers would be stored in the Seat Number table. This generated Seat Numbers can be used for the purpose of Generation of hall ticket.

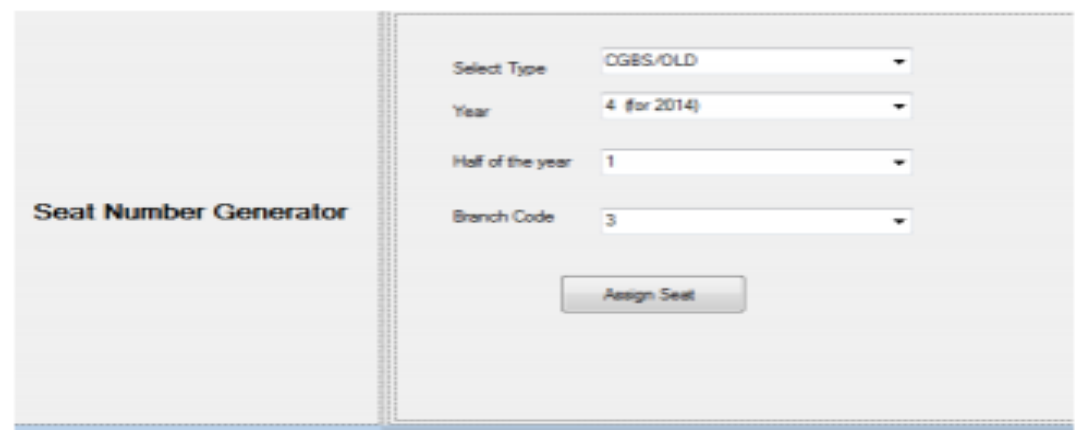

Fig. 5.1 Seat Number Generation System

DOI Number: https://doi.org/10.30780/specialissue-SCRDSI-2021/006 


\subsection{Generation of Result}

Admin can generate results by clicking result option when his information in login process get verified. In order to view result, admin has to select semester, year and subject etc. of a particular student whose result needs to be generated. The ERP module will check all the details in the database, retrieve the data related to result and process the data as per the requirement and finally display the result. Once the result can be generated admin can analyze and acquire reports on the performance of the result.

\section{LIMITATIONS}

Students have to either correspond through postal mail or visit university even for minor queries regarding examinations. Sometimes due to increased paper load in the examination branches their correspondences/applications are not traceable. The personal visit to universities wastes a Himachal Pradesh University Journal, July 20115 student's precious time and money and cause unnecessary harassment. It is a common sight to find students jostling near university in various service windows purchasing examination forms, depositing examination fee and to get to know the status of their results.

$>$ The manual examination system leads to errors, more time consumption, inefficient and wastage of valuable resources. Moreover, ever increasing paper based record registers are difficult to store securely due to space scarcity.

$>$ There is repetition of work in the existing system because the same data is recorded in different branches of the examination. This leads to data duplications as well as huge money is spent by the university to purchase papers. In existing system, managing of students' record is very tedious. Retrieval of students' records through manual registers, maintaining of records and data reconciliation etc. are very time consuming.

$>$ In manual examination system, there remain chances of tempering of students records. Sometimes fake degrees are prepared and there is no online verification of the same. This leads to unfair practices and also it mars the credibility of a university

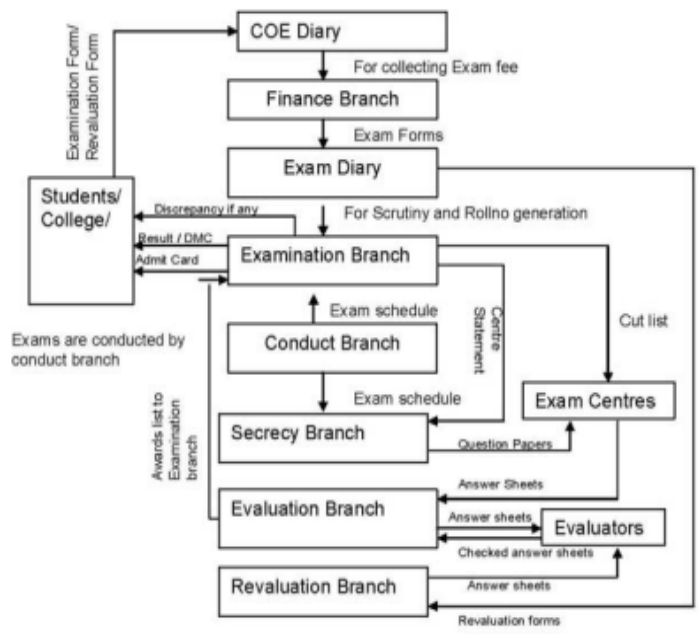

Fig. 6.1 Organization of Manual Examination System

\section{AN ALTERNATE APPROACH}

Some of the common tangible benefits by switching over to the alternate approach based upon automation and integrating the examination systems, which we rechristen as Automated Integrated Examination System (AIES) to differentiate it from manual examination system can be put as bullet points below:

$>$ Total automation of the system will facilitate integration of all branches physically, though logically these branches may keep functioning as before.

$>$ The new system will streamline the procedure for collation of exam fees, issuing receipts to large number of students and keeping a track of cash flow. There will be centralized, secure and robust database of the candidates appearing in the examination without duplication of records.

$>$ It will bring improvement in quality of services to the stakeholders by introducing computerized window system and online availability of information.

$>$ The complete Computerization of Examination System will lead to effective monitoring of examination processes by the concerned authorities and the possibility of fraudulence will be minimized.

$>$ The computerized statistical analysis of data will enable the management to see trends in result at various levels and timely availability of compiled reports can be used to make strategic decisions in favor of university and students. 


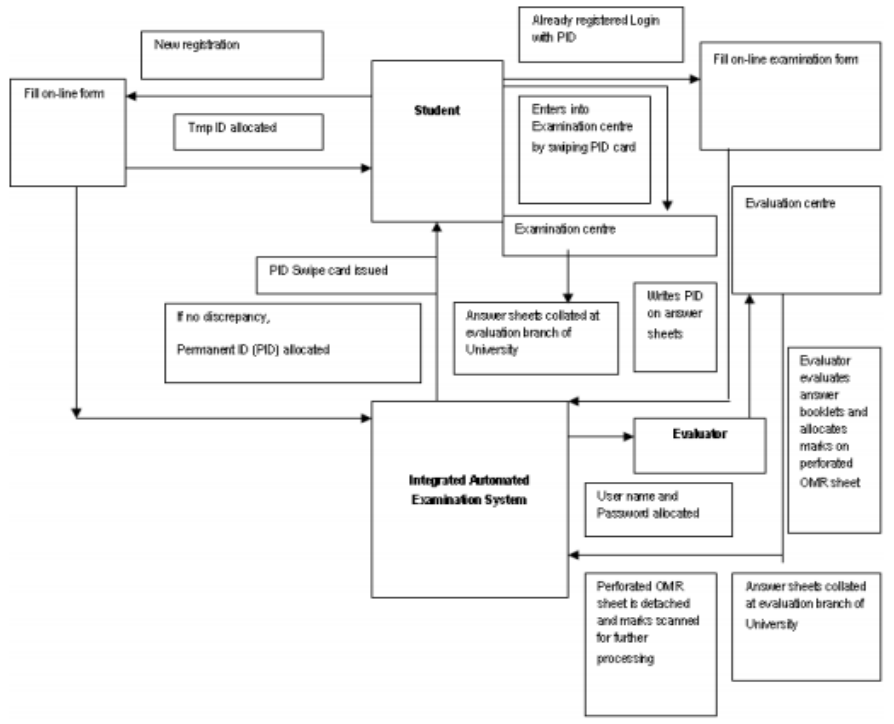

Fig. 7.1 Automated Integrated Examination System

\section{CONCLUSION}

Considering the extremely interwoven nature of exam cell activities, an automated solution to important activities like result analysis and report generation would greatly benefit the institution. The use of up-to-date open-source software ensures a great cost-benefit measure while maintaining productivity, thus improving the student experience and value of education. Further, the implementation of this system can perpetuate the automation of other important activities in the institute, thus making the college more student and staff-friendly. We have been successful in deploying the entire form filling and hall ticket module on intranet. About the result analysis module, two types of analysis are done: - subject wise and semester wise. For the subject wise analysis, we have for a particular semester, it's all subjects and its analysis in terms of various grades obtained and in terms of pass percentage of each subject and overall pass percentage of students in a particular semester. The deployment of form filling module saw a drastic reduction in the amount of time which was taken to fill up the exam form and then submitting it. The module was built keeping in mind all possible mistakes a user can make and the system thus developed was user friendly.

\section{REFERENCES}

[1] "ERP implementation critical success factors-the role and impact of business process management" Management of Innovation and Technology, 2000. ICMIT 2000. Proceedings of the 2000 IEEE International Conference on (Volume: 1) pg122 - 127.

[2] Bingi P., Sharma M., Godla J. "Critical Issues Affecting an ERP Implementation", Information Systems Management, (16:3), Summer 1999.

[3] Bhardwaj Mohini, Singh Amar Jeet (2008), "E-Governance: Single Portal for Integrated Examination System", Emerging Technology in E-Government, G.P. Sahu, pp.288-293.

[4] Bhardwaj Mohini, Singh Amar Jeet (2008), "Automated Integrated Examination System: A Security Concern" Information Security Journal: A Global Perspective, Taylor \& Francis, Volume 20 Issue 3, January 2011, pp 156-162.

[5] Hallak, J. and Poisson, M. (2007). Academic Fraud, Accreditation and Quality Assurance. Learning from the Past and Challenges for the Future. Higher Education in the World, pp. 109-122.

[6] Bhardwaj Mohini, Singh Amar Jeet (2008), "E-Governance: Single Portal for Integrated Examination System", Emerging Technology in E-Government, G.P. Sahu, pp.288-293

[7] Mishra, N. L. (1988). Organization and Management of University Examinations, National Publishing House, Jaipur (Raj.), India.

[8] Maki Christiana (2008)," Information and Communication Technology for Administration and Management for secondary schools in Cyprus", Journal of Online Learning and Teaching Vol. 4 No. 3.

[9] Mishra, N. L. (1988). Organization and Management of University Examinations, National Publishing House, Jaipur (Raj.), India. President (2004).

[10] Education for dignity of human life. President Dr. A. P. J. Abdul Kalam's Address to the Nation o the eve of 58th IndependenceDay2004.

[11] Ulf Frederickson and ElżbietaGajek (2009)," Ways to use ICT in schools to optimize the impact on teaching and learning", Paper presented at ECER, September 28 - 30 in Vienna, Austria.

[12]ZainallyHossein (2008)," Administration of Faculties by Information and Communication Technology and Its Obstacles", International Journal of Education and Information Technologies, Vol.2,issue1,2008. 